\title{
Carbon-Based Fibrous EDLC Capacitors and Supercapacitors
}

\author{
C. Lekakou, O. Moudam, F. Markoulidis, T. Andrews, J. F. Watts, and G. T. Reed \\ Faculty of Engineering and Physical Sciences, University of Surrey, Guildford, Surrey GU2 7XH, UK \\ Correspondence should be addressed to C. Lekakou, c.lekakou@surrey.ac.uk
}

Received 4 February 2011; Accepted 20 March 2011

Academic Editor: Huisheng Peng

Copyright $\odot 2011$ C. Lekakou et al. This is an open access article distributed under the Creative Commons Attribution License, which permits unrestricted use, distribution, and reproduction in any medium, provided the original work is properly cited.

\begin{abstract}
This paper investigates electrochemical double-layer capacitors (EDLCs) including two alternative types of carbon-based fibrous electrodes, a carbon fibre woven fabric (CWF) and a multiwall carbon nanotube (CNT) electrode, as well as hybrid CWF-CNT electrodes. Two types of separator membranes were also considered. An organic gel electrolyte PEO-LiCIO 4 -EC-THF was used to maintain a high working voltage. The capacitor cells were tested in cyclic voltammetry, charge-discharge, and impedance tests. The best separator was a glass fibre-fine pore filter. The carbon woven fabric electrode and the corresponding supercapacitor exhibited superior performance per unit area, whereas the multiwall carbon nanotube electrode and corresponding supercapacitor demonstrated excellent specific properties. The hybrid CWF-CNT electrodes did not show a combined improved performance due to the lack of carbon nanotube penetration into the carbon fibre fabric.
\end{abstract}

\section{Introduction}

There is much interest in electrochemical double-layer capacitors (EDLCs) due to the quick response and high mobility of the ions of the electrolyte and the increase of energy storage due to the double capacitor layer effect. Carbon-based electrodes attract a lot of research as they offer the possibility of a good conductor of large surface area. Much research has focused on porous carbon electrodes [15] which supply large surface area but are poor conductors, offering reduced power density. The next step is to consider fibrous carbon materials [6] of good conductivity to ensure high power density, whereas the high surface area of their fibrous structure could provide good energy density. Such materials have the advantage of having been considered and applied in the field of structural composites from which there is a wealth of research and expertise on their processing and their impregnation by viscous and viscoelastic fluids [7-9]. Furthermore, there is increased interest in fibrous materials and textiles for wearable electronics for everyday use, biomedical monitoring and, other specific applications for which a wearable unit for energy storage and supply would be most useful. As a result, it would be worthwhile to explore the use of carbon-based fibrous materials as EDLC electrodes. Shirshova et al. [10] tested high conductivity, nonactivated carbon fibre fabrics as electrodes for capacitor devices with a polymer gel electrolyte, poly(ethylene glycol) diglycidyl ether (PEGDGE), which resulted in very low capacitance, whereas their activated carbon fabrics had high resistance.

Carbon nanotubes have the advantage of forming electrically conductive networks and possibly being able to also store energy [11]. Pushparaj et al., 2007 [12], used as electrode MWNTs aligned perpendicularly to the current collector and embedded in cellulose, and they fabricated supercapacitors with a maximum power density of $1.5 \mathrm{~kW} / \mathrm{kg}$ for an RTIL electrolyte. Shi et al. [13] reported that growing carbon nanotubes directly on the nickel foam current collector lowered the internal resistance. Ma et al. [14] reported the inclusion of MWNTs in phenolic resin mixtures and carbonisation of the mixture at $850^{\circ} \mathrm{C}$, which yielded electrodes of a specific capacitance of $15-25 \mathrm{~F} / \mathrm{cm}^{3}$ using $38 \mathrm{wt} \% \mathrm{H}_{2} \mathrm{SO}_{4}$ as electrolyte. Binderless carbon or MWNT electrodes [15] have been considered, and they might have lower resistance in the absence of a polymeric binder while they are also of lower cost. However, the results of Bordjiba et al. [15] cannot be compared directly to the results of the present study, as they used mainly activated carbon as their electrode and only a small percentage of MWNTs and an aqueous $\mathrm{KOH}$ electrolyte, whereas the present study uses nonactivated fibrous carbon electrodes and an organic 
electrolyte. Guo et al. [16] found that carbon nanotubes embedded in electrospun carbon nanofibres (CNFs) doubled the capacitance of CNFs using $1 \mathrm{M} \mathrm{H}_{2} \mathrm{SO}_{4}$ electrolyte.

The electrolyte is very important in the performance of a capacitor, and more specifically the ion mobility and the electrochemical stability of the electrolyte (defining the potential range of use of the electrolyte). Aqueous electrolytes have low electrical resistance, high ion mobility but low maximum voltage around $1 \mathrm{~V}$ [17]. This means that they are highly suitable for very low voltage applications but for medium and high voltage applications assemblies of many in-series connected low voltage cells are required for the capacitor bank. An in-series connection of $N$ cells with a cell capacitance $C$ and a cell resistance $R$ reduces the total capacitance to $C / N$ and increases the total resistance to NR. Hence, this study has included an organic electrolyte with relatively high working voltage. Lithium ion electrolytes have been used in both battery and capacitor applications. The anion $\mathrm{CIO}_{4}$ has moderate binding ability with aprotic solvents [18]. The PMMA-EC-PC-TEAClO ${ }_{4}$ gel electrolyte has a working potential range of -2.5 to $+2.5 \mathrm{~V}$ and exhibited a maximum capacitance of $3.7-5.4 \mathrm{mF} \mathrm{cm}^{-2}$ [19]. Polyethylene oxide is an ionomer supplying anions [18], hence, it has been incorporated in the gel electrolyte in this study. Furthermore, ion mobility in a porous electrode is linked to the relative sizes of pores and ions [20]. In recent studies [21, 22], $\mathrm{TEABF}_{4}$ is a popular organic electrolyte that can be used in cyclic voltammetry up to $3 \mathrm{~V}$ without any degradation; however, the size of $\mathrm{TEA}^{+}$is rather large [20] in comparison with the size of $\mathrm{Li}^{+}$ions and ions of aqueous electrolytes, hence it was decided to use a $\mathrm{Li}^{+}$-based organic electrolyte in this study. Further developments on supercapacitors in latest studies are based on adding pseudocapacitance compounds to the carbon fibrous electrodes $[22,23]$ which increase the overall capacitance but introduce redox processes that would reduce the lifetime of the capacitor device.

The present study considers the fabrication and testing of novel EDLC cells with carbon-based fibrous electrodes without any binder, two different types of separator membranes, and an organic gel electrolyte, $\mathrm{PEO}-\mathrm{LiCiO}_{4}$-EC-THF. Two different types of electrically conductive fibrous carbon material were explored as electrodes on their own or as a combination: a carbon fibre plain woven fabric (CWF) and multiwall carbon nanotubes (MWNTs). The purpose of the organic gel electrolyte was a relatively high working voltage, fast moving small $\mathrm{Li}^{+}$ions and the fabrication of a homogeneous, compliant EDLC. The carbon fibre fabric consisted of tows comprising many microfibres and resulting in a structure of dual porosity including meso- and micropores. Impregnation of this fabric by a viscous electrolyte would be channelled preferentially into the mesopores and might leave unfilled micropores [24, 25]. As a result, care was taken during the fabrication to perform impregnation slowly and for a long time to ensure maximum impregnation of microspores. In the case of MWNTs, dispersion was very important to achieve maximum surface area and maximum number of conductive paths in the MWNT network. Two types of separator membranes were used alternatively: a filter membrane with $0.8 \mu \mathrm{m}$ pores and a glass microfibre filter
(GF/F) with $0.7 \mu \mathrm{m}$ average pore size. All EDLC cells were tested in cyclic voltametry, charge-discharge, and impedance tests. Two EDLC cells exhibited excellent performance: the CWF-GF/F cell demonstrated excellent performance per unit area, and the CNT-GF/F cell demonstrated excellent specific properties (per unit mass).

\section{Materials}

2.1. Carbon Fibre Plain Woven Fabric Electrodes. An engineering carbon fibre fabric was used of plain weave, A0186, from Folthergill Engineered Fabrics, of a nominal thickness of $270 \mu \mathrm{m}$ and areal density of $19.9 \mathrm{mg} / \mathrm{cm}^{2}$. The carbon fabric was used as received, and the carbon was not activated in any way.

2.2. Carbon Nanotube (CNT) Electrodes. Multiwall carbon nanotubes (MWNTs) ElicarbMW from Thomas Swan Ltd were used, with the following parameters: outer diameter of $10-30 \mathrm{~nm}$, tens of microns length, and $>92 \%$ purity. In a previous dielectrophoresis study in Araldite epoxy by our group [26], it was determined that they have high electrophoretic mobility $\mu=0.0025 \mu \mathrm{mmm} / \mathrm{Vs}$ and zeta potential of $67 \mathrm{mV}$.

In this study, $0.3 \% \mathrm{w} / \mathrm{v}$ MWNTs were dispersed in THF first via sonication for $1 \mathrm{hr}$ and afterwards via high shear mixing at $18,000 \mathrm{rpm}$ for $1 \mathrm{hr}$. The mixture was deposited with a syringe drop by drop onto an aluminium tape current collector. THF was allowed to evaporate, and a thin MWNT mat was formed.

\subsection{Separator. Two types of separators were tried:}

Super poly(estersulphone) filter membrane by PALL: $0.8 \mu \mathrm{m}$ pores, measured thickness of $290 \mu \mathrm{m}$;

GF/F filter, a glass microfibre filter by Whatman with $0.7 \mu \mathrm{m}$ average pore size and a nominal thickness of $420 \mu \mathrm{m}$.

2.4. Electrolyte. The electrolyte was a PEO- $\mathrm{LiClO}_{4}$-EC-THF organic gel electrolyte consisting of $0.5 \mathrm{~g}$ polyethylene oxide $\left(\mathrm{PEO}, M_{v}=100,000, n_{d}=1.45\right), 0.21 \mathrm{~g} \mathrm{LiClO}_{4}$, and $0.29 \mathrm{~g}$ ethylene carbonate (EC) in $10 \mathrm{~mL}$ THF. All substances were purchased from Sigma-Aldrich. Processing of the electrolyte was carried out after gently heating it as EC solidifies at $35^{\circ} \mathrm{C}$.

\section{Experimental Methods}

3.1. Fabrication of Capacitor Cells. Figure 1 presents the EDLC capacitor cells fabricated and tested in this study. In each case, the separator porous membrane was dip-coated in the electrolyte gel, sandwiched between the electrodes, and the whole cell was sealed under gradually increasing pressure up to $5 \mathrm{kPa}$. Generally, each carbon fibre woven fabric-based capacitor cell was $2 \mathrm{~cm}^{2}$, and each CNT-based capacitor cell was $1 \mathrm{~cm}^{2}$. 


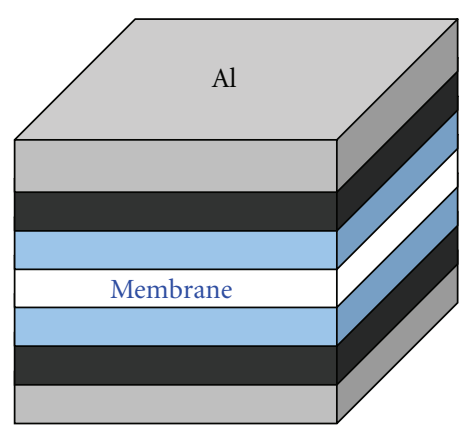

(a)
Carbon fibre fabric

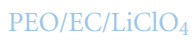

$\mathrm{PEO} / \mathrm{EC} / \mathrm{LiClO}_{4}$ Carbon fibre fabric

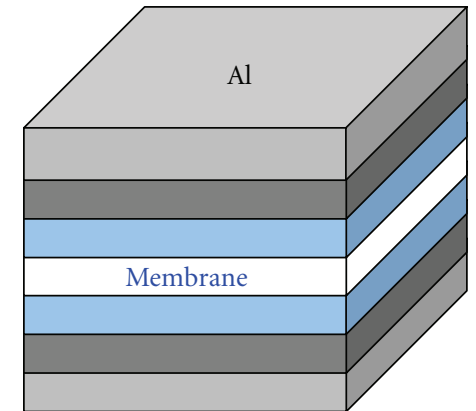

(b)

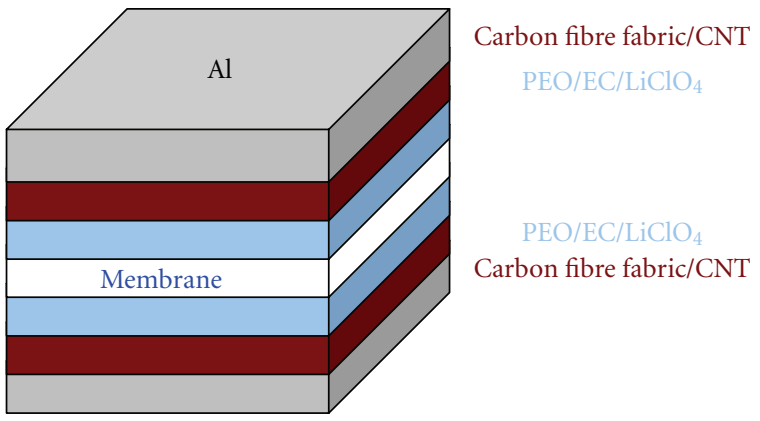

(c)

FIGURE 1: Diagrams of EDLC cells fabricated and tested in this study.

The following types of capacitor cells were fabricated and tested:

(i) carbon fibre woven fabric electrodes and GF/F filter separator (CFW-GF/F);

(ii) carbon fibre woven fabric electrodes and Supor filter separator (CFW-Supor);

(iii) carbon nanotube electrodes and GF/F filter separator (CNT-GF/F);

(iv) carbon nanotube electrodes and Supor filter separator (CNT-Supor);

(v) hybrid CFW-CNT electrodes and GF/F filter separator (CFW-CNT-GF/F);

(vi) hybrid CFW-CNT electrodes and Supor filter separator (CFW-CNT-Supor).

3.2. Testing of the Capacitor Cells. The fabricated capacitor cells were tested using a VersaSTAT4 Electrochemical System in cyclic voltametry, charge-discharge, and impedance tests. Cyclic voltametry $(\mathrm{CV})$ was performed initially within 0 to $+3 \mathrm{~V}$ to find the maximum breakdown potential of the electrolyte and subsequently within 0 to $2.5 \mathrm{~V}$. The area of the I-V envelope gave the power, $P$, and power density, $P_{\mathrm{sp}}$, of the full capacitor cell (by dividing by the mass of the two carbon-based electrodes). Considering the current at the midpoint, $I_{m}$, and the scan rate, $d V / d t$, the capacitance, $C_{\mathrm{CV}}$, was determined:

$$
C_{\mathrm{CV}}=\frac{I_{m}}{d V / d t} .
$$

Charge-discharge tests were also used to determine capacitance:

$$
C_{\mathrm{CD}}=\frac{I}{d V / d t}
$$

while impedance, $Z$, testing provided more data of the capacitance as function of frequency, $f$ (angular frequency $\omega=2 \pi f)$, where

$$
Z=Z^{\prime}+j Z^{\prime \prime},
$$

the real part of impedance $Z^{\prime}$ is the resistance $R$, the imaginary part of impedance, $Z^{\prime \prime}$, is the sum of the capacitive reactance $X_{C}$ (depending on capacitance $C$ ) and the inductive reactance $X_{L}$ (depending on inductance $L$ ):

$$
\begin{gathered}
C=-\frac{1}{\omega X_{C}}, \\
X_{L}=\omega L .
\end{gathered}
$$

The maximum energy $E_{\max }$ stored in the capacitor is given by

$$
E_{\max }=\frac{1}{2} C V_{\max }^{2} .
$$

The maximum power of the capacitor $P_{\max }$ depends on its equivalent series resistance ESR according to the relation, where ESR values in this study included both electrolyte and interface resistances:

$$
P_{\max }=\frac{V^{2}}{4 \mathrm{ESR}} .
$$




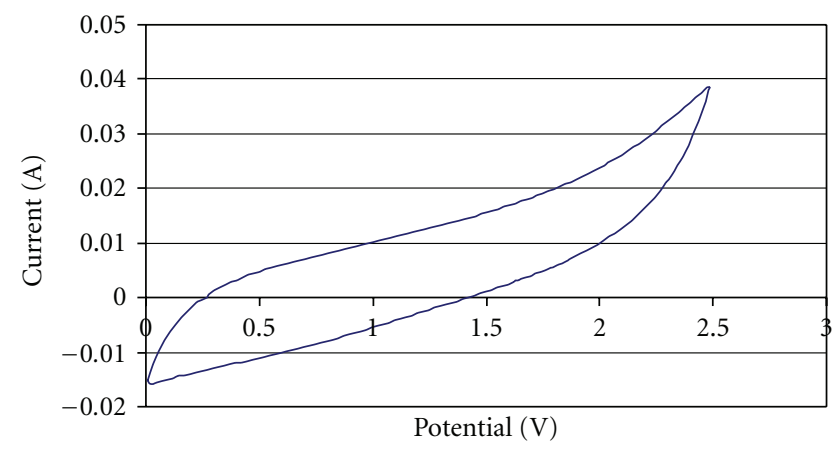

(a)

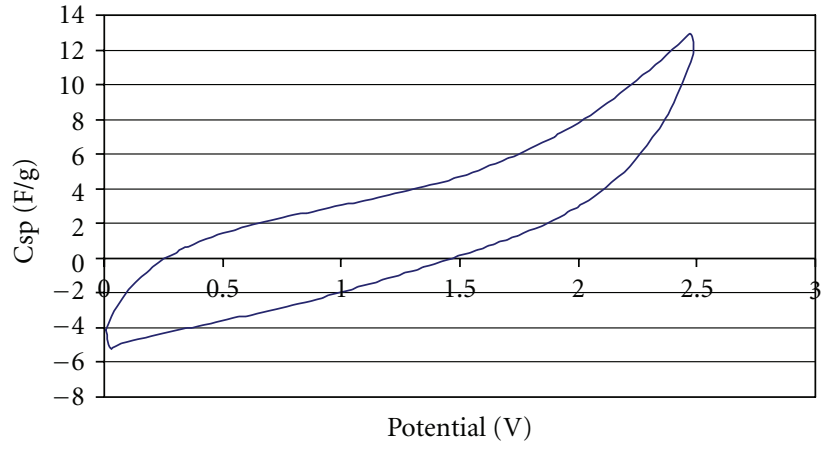

(b)

Figure 2: Cyclic voltametry of EDLC CWF-GF/F capacitor from 0 to $2.5 \mathrm{~V}$ at a rate of $0.15 \mathrm{~V} / \mathrm{s}$ and specific capacitance of electrode; each carbon electrode has an area of $2 \mathrm{~cm}^{2}$ and mass of $40 \mathrm{mg}$.

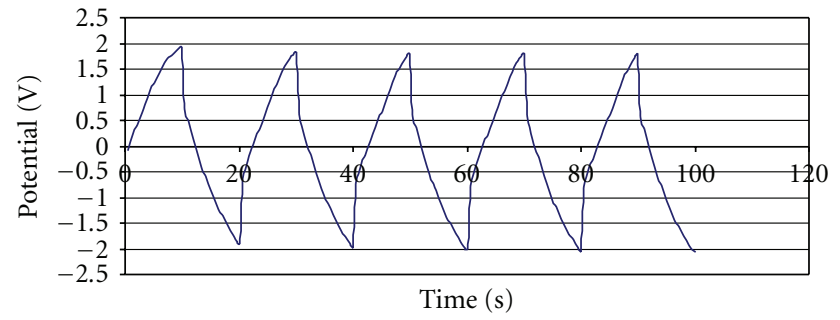

FIgURE 3: Charge-discharge testing of EDLC CWF-GF/F capacitor at constant current steps of $-5 \mathrm{~mA}$ and $+5 \mathrm{~mA}$; each carbon electrode has an area of $1 \mathrm{~cm}^{2}$ and mass of $20 \mathrm{mg}$.

\section{Results}

4.1. Carbon Fibre Woven Fabric- (CFW-) Based Capacitors. Figure 2 presents the results from cyclic voltametry for the CWF-based electrode capacitors with a GF/F filter as separator. From the plots, a maximum potential of $2.3 \mathrm{~V}$ may be considered for the electrolyte of $\mathrm{LiClO}_{4} / \mathrm{EC} / \mathrm{PEO}$, which is higher than previously reported ( $1 \mathrm{~V}$ for [27] using $\mathrm{LiClO}_{4}{ }^{-}$ EC-PC-Polyurethane electrolyte) for similar electrolytes in a carbon cloth electrode, demonstrating the excellent pairing of the electrolyte and the CWF electrode in this study. In fact, the present study has reached the highest possible potential for $\mathrm{LiClO}_{4}$, where beyond this, electrolyte breakdown occurs.

Figure 3 presents the results of the charge-discharge test from which the electrode capacitance has been determined as $C_{\text {Discharge, } \max }=0.076 \mathrm{~F} / \mathrm{cm}^{2}$ or $3.81 \mathrm{~F} / \mathrm{g}$. This yields the corresponding energy $E=0.20 \mathrm{~J} / \mathrm{cm}^{2}$ and $E_{\mathrm{sp}}=2.8 \mathrm{Wh} / \mathrm{kg}$.

Figure 4 displays the Nyquist plot from the impedance testing of an EDLC CWF-GF/F capacitor, which displays an ESR of $6.1 \mathrm{ohm}$, yielding a maximum power density for the EDLC cell of $2.7 \mathrm{~kW} / \mathrm{kg}$. Figure 5 presents the AC capacitance of the EDLC CWF-GF/F cell as a function of AC frequency, showing that there is a large fall of capacitance of two orders of magnitude within the first $500 \mathrm{~Hz}$, thereafter the capacitance falls much more slowly. In general, the results of capacitance, power density, and energy density for the EDLC CWF-GF/F electrode and capacitor cell demonstrate that

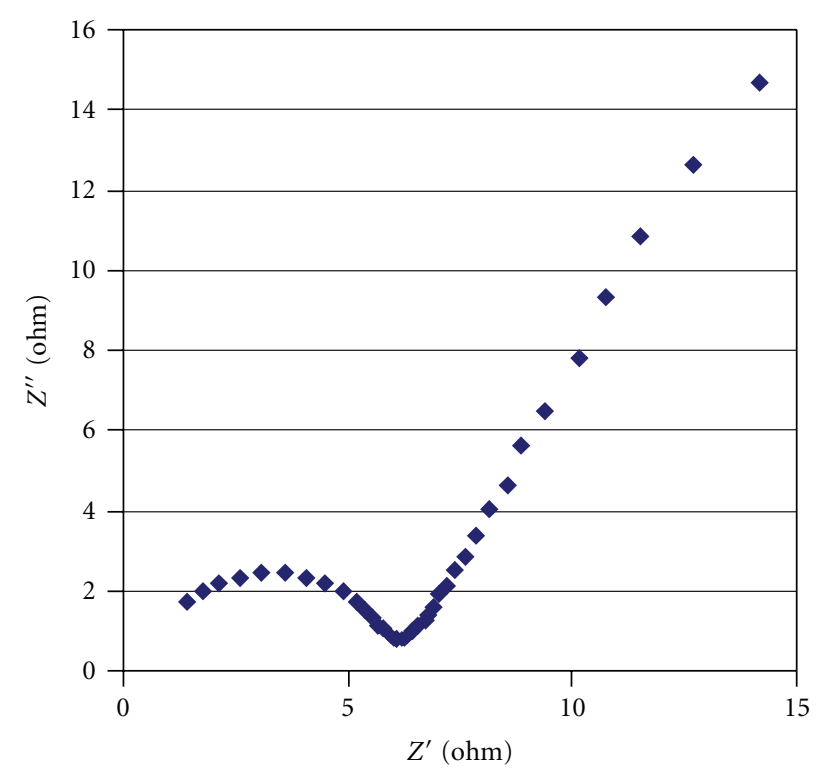

FIGURE 4: Nyquist plot from impedance testing of EDLC CWF-GF/F capacitor between $10 \mathrm{kHz}$ and $1 \mathrm{~Hz}$; each carbon electrode has an area of $2 \mathrm{~cm}^{2}$ and mass of $40 \mathrm{mg}$.

its performance is higher than other fibre fabric capacitors reported in the literature (e.g., several orders of magnitude better than Shirshova et al.'s work [10]) and that it is at the levels of current commercial supercapacitors.

The same experiments were repeated using as separator the thinner Supor poly(estersulphone) filter membrane. The main performance results are presented in Table 1. It is clear that the EDLC CWF-Supor cell is inferior in both ESR and capacitance, yielding much lower power and energy densities. It is thought that the reason for this is the large surface area of the microfiber GF/F filter separator and its large absorbance of the electrolyte, which lowers ESR while it also increases capacitance. These good properties of the glass fibre papers have also been observed by other investigators with different electrolytes (e.g., Staiti et al. [28] with $\mathrm{H}_{2} \mathrm{SO}_{4}$ as electrolyte). 
TABLE 1: Summary of performance results of the various types of electrodes combined with two different types of separators. $\left(P_{\mathrm{CV}}\right.$ : power from cyclic voltametry 0 to $2.5 \mathrm{~V}$ at $0.2 \mathrm{~V} / \mathrm{s}$. $P_{\mathrm{CV}}$, sp: power density from cyclic voltametry at $0.2 \mathrm{~V} / \mathrm{s}$. $P_{\max }$ : maximum power on the basis of the ESR determined from the impedance test. $P_{\max , \mathrm{sp}}$ : maximum power density. $E_{\max }$ : maximum energy. $E_{\max , \text { sp }}$ : maximum energy density).

\begin{tabular}{lcccccc}
\hline Cell & CFW-GF/F & CFW-Supor & CNT-GF/F & CNT-Supor & CFW-CNT-GF/F & CFW-CNT-Supor \\
\hline$P_{\mathrm{CV}}\left(\mathrm{W} / \mathrm{cm}^{2}\right)$ & $0.035_{0.15 \mathrm{~V} / \mathrm{s}}$ & 0.012 & 0.004 & 0.004 & 0.004 & 0.006 \\
$P_{\mathrm{CV}, \mathrm{sp}}(\mathrm{kW} / \mathrm{kg})$ & $1.768_{0.15 \mathrm{~V} / \mathrm{s}}$ & 0.320 & 20 & 1.84 & 0.245 & 0.265 \\
$P_{\max }\left(\mathrm{W} / \mathrm{cm}^{2}\right)$ & 0.207 & 0.012 & 0.011 & 0.024 & 0.01 & 0.014 \\
$P_{\max , \mathrm{sp}}(\mathrm{kW} / \mathrm{kg})$ & 10.4 & 0.292 & 113 & 12.1 & 0.52 & 0.60 \\
\hline$C_{\mathrm{CV}}\left(\mathrm{F} / \mathrm{cm}^{2}\right)$ & $0.08_{0.15 \mathrm{~V} / \mathrm{s}}$ & 0.015 & 0.002 & 0.008 & 0.053 & 0.008 \\
$C_{\mathrm{CV}, \mathrm{sp}}(\mathrm{F} / \mathrm{g})$ & $3.78_{0.15 \mathrm{~V} / \mathrm{s}}$ & 0.095 & 12.487 & 5.2 & 2.6 & 0.38 \\
$C_{\mathrm{D}}\left(\mathrm{F} / \mathrm{cm}^{2}\right)$ & $0.08_{5 \mathrm{~mA} / \mathrm{cm}^{2}}$ & No test & $0.001_{20 \mu \mathrm{A} / \mathrm{cm}^{2}}$ & No test & No test & No test \\
$C_{\mathrm{D}, \mathrm{sp}}(\mathrm{F} / \mathrm{g})$ & $3.81_{5 \mathrm{~mA} / \mathrm{cm}^{2}}$ & No test & $6.39_{20 \mu \mathrm{A} / \mathrm{cm}^{2}}$ & No test & No test & No test \\
\hline$E\left(\mathrm{~J} / \mathrm{cm}^{2}\right)$ & $0.20_{0.15 \mathrm{~V} / \mathrm{s}}$ & 0.040 & 0.007 & 0.02 & 0.085 & 0.013 \\
$E_{\max , \mathrm{sp}}(\mathrm{Wh} / \mathrm{kg})$ & $2.80_{0.15 \mathrm{~V} / \mathrm{s}}$ & 0.280 & 9.2 & 2.94 & 1.17 & 0.164 \\
\hline
\end{tabular}

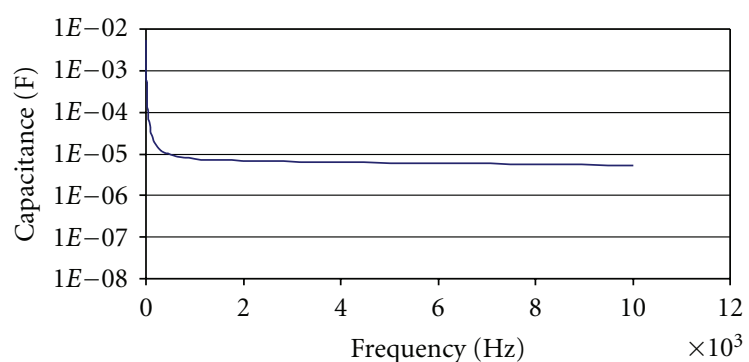

Figure 5: Capacitance as a function of frequency from impedance testing of EDLC CWF-GF/F capacitor between $10 \mathrm{kHz}$ and $1 \mathrm{~Hz}$; each carbon electrode has an area of $2 \mathrm{~cm}^{2}$ and mass of $40 \mathrm{mg}$.

4.2. Carbon Nanotube- (CNT-) Based Capacitors. First, EDLC cells were fabricated with CNT electrodes (deposited on $\mathrm{Al}$ current collectors) and a GF/F filter separator. The cells were subjected to cyclic voltametry, charge-discharge, and impedance tests. Figure 6 presents the results from cyclic voltametry plotted as current versus potential and capacitance versus potential graphs. From the graphs, a maximum potential of $2.3 \mathrm{~V}$ may be considered for the electrolyte of $\mathrm{LiClO}_{4} / \mathrm{EC} / \mathrm{PEO}$, same as for the CWF electrodes. The I-V curves display a bump at -1.1 and $+1.1 \mathrm{~V}$, indicating redox reactions at the CNTs. The first results show clearly that the areal power and capacitance (per $\mathrm{cm}^{2}$ ) are lower than the corresponding properties of the CWF-GF/F cell (see Table 1) but the CNT-GF/F cell has much higher specific properties, such as power density, $P_{\mathrm{sp}}$, and specific capacitance, $C_{\mathrm{sp}}$, due to the very small mass of each CNT electrode.

Figure 7 presents the results of the charge-discharge test from which the capacitance has been determined as $C_{\text {Discharge, } \max }=0.0013 \mathrm{~F} / \mathrm{cm}^{2}$ or $6.39 \mathrm{~F} / \mathrm{g}$. This yields the corresponding energy $E=3.4 \mathrm{~mJ} / \mathrm{cm}^{2}$ and $E_{\text {sp }}=4.7 \mathrm{Wh} / \mathrm{kg}$ with excellent charge/discharge energy efficiency at $97 \%$.

Figure 8 displays the Nyquist plot from the impedance testing of an EDLC CNT-GF/F capacitor cell, which displays clear supercapacitor behaviour with an ESR of $0.5 \mathrm{ohm}$, yielding a maximum power density of $28.3 \mathrm{~kW} / \mathrm{kg}$ for the full cell. Figure 9 presents the AC capacitance of the full EDLC cell as a function of AC frequency. It is evident that the EDLC CNT-GF/F cells behave as supercapacitors, as far as power and energy densities are concerned, and they have an energy density of $2.3 \mathrm{Wh} / \mathrm{kg}$.

When the Supor filter is used as a separator, the EDLC CNT-Supor cells (each electrode: $1 \mathrm{~cm}^{2}$ and $2 \mathrm{mg}$ ) display much worse performance than the EDLC CNT-GF/F cells, in a similar way as the EDLC carbon woven fabric-based cells (see Table 1).

4.3. Hybrid Carbon Woven Fabric-Carbon Nanotube- (CWFCNT-) Based Capacitors. Figure 10 presents cyclic voltametry results for the CFW-CNT-GF/F cell, which clearly exhibits very low power and a maximum potential of $1.8 \mathrm{~V}$. The low performance of the cell is repeated also in the Nyquist plot in Figure 11, where it is evident that the cell has several interface resistances, because of multiple types of interfaces of carbon fabric and CNTs, due to the poor penetration of CNTs in CFW. Furthermore, even in the low frequency region, there is very high loss and consequently current loss.

The EDLC CWF-CNT-Supor cells also showed a maximum operating potential of only $1.8 \mathrm{~V}$ and exhibited an ESR of $118 \mathrm{ohm}$, yielding $P_{\max }=0.014 \mathrm{~W} / \mathrm{cm}^{2}$ and $P_{\max , \text { sp }}=$ $0.60 \mathrm{~kW} / \mathrm{kg}$. The addition of MWNTs to the carbon fibre electrode did not yield any considerable improvements with the Supor filter as separator (CWF-CNT-Supor) in the fabricated EDLC cells. The cells exhibited capacitance similar to that of the CNT-Supor cells but with a lower maximum potential of $1.8 \mathrm{~V}$ which would decrease both power and energy. Furthermore, the mass of electrodes includes the large mass of the carbon fibre fabric without it contributing really to the capacitance; as a result, the specific properties and energy density are reduced. However, the addition of MWNTs reduces the ESR, increasing $P_{\max }$ (even with lower maximum working potential) and the power density.

\section{Conclusions}

EDLC cells were fabricated with carbon-based fibrous electrodes. Two types of separator membranes were tried: a Supor poly(estersulphone) microporous membrane and 


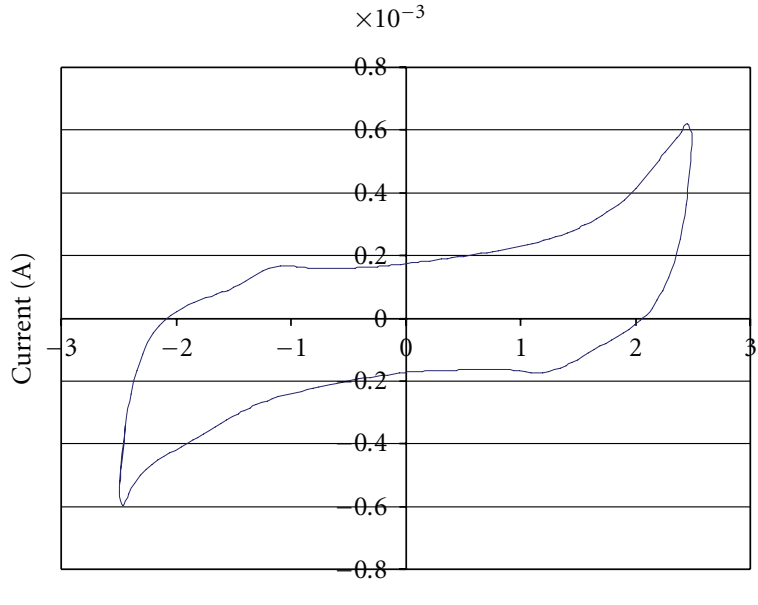

Potential (V)

(a)

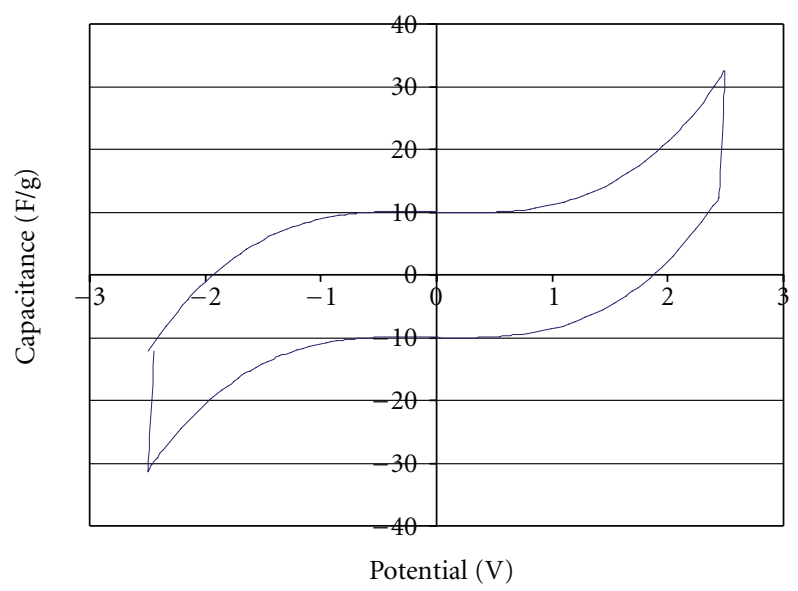

(b)

Figure 6: Cyclic voltametry of EDLC CNT-GF/F capacitor from 0 to $2.5 \mathrm{~V}$ at a rate of $0.2 \mathrm{~V} / \mathrm{s}$ and specific capacitance of electrode; each CNT electrode has an area of $1 \mathrm{~cm}^{2}$ and mass of $0.2 \mathrm{mg}$.

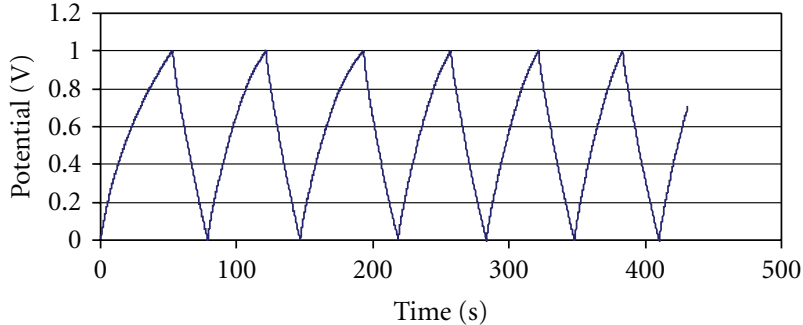

FIGURE 7: Charge-discharge testing of EDLC CNT-GF/F capacitor at constant current steps of $-20 \mu \mathrm{A}$ and $+20 \mu \mathrm{A}$; each carbon electrode has an area of $1 \mathrm{~cm}^{2}$ and mass of $0.2 \mathrm{mg}$.

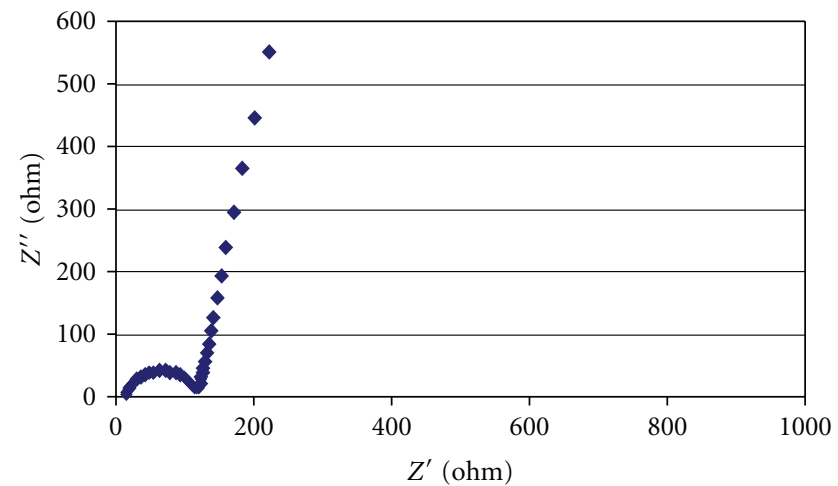

FIGURE 8: Nyquist plot from impedance testing of EDLC CNT-GF/F capacitor between $100 \mathrm{kHz}$ and $0.1 \mathrm{~Hz}$; each carbon electrode has an area of $1 \mathrm{~cm}^{2}$ and mass of $0.2 \mathrm{mg}$.

a GF/F glass microfibre filter. The GF/F separator proved most successful, and its high performance in the EDLC cells could be attributed to the large surface area of its microfibrous material. A PEO-LiCiO 4 -EC-THF gel electrolyte was used that exhibited high maximum voltage of $\pm 2.3 \mathrm{~V}$ for the

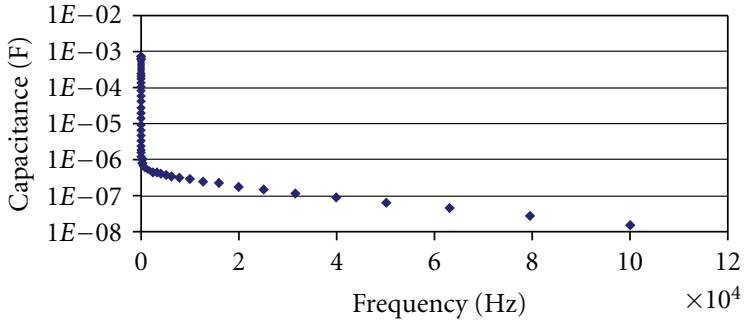

Figure 9: Capacitance as a function of frequency from impedance testing of EDLC CNT-GF/F capacitor cell between $100 \mathrm{kHz}$ and $0.02 \mathrm{~Hz}$; each carbon electrode has an area of $1 \mathrm{~cm}^{2}$ and mass of $0.2 \mathrm{mg}$.

CWF and CNT electrodes, although some small bumps were present in the cyclic voltametry tests of the CNT electrodes at $\pm 1.1 \mathrm{~V}$ indicating redox reactions. The best types of EDLC cells were the CWF-GF/F cells which demonstrated superior capacitance, energy, and power per unit area $\left(\right.$ per $\left.\mathrm{cm}^{2}\right)$ and the CNT-GF/F cells which demonstrated excellent specific capacitance, power density, and energy density. Data for these two best cells were assembled into the Ragone plots presented in Figure 12. The MWNT electrode has excellent specific properties but, due to its low density, a large area of electrode needs to be coated to achieve the same area-based performance of a carbon fabric EDLC. On the other hand, a carbon fibre fabric can be readily used as electrode, or part of it can be used for a wearable capacitor in wearable or fitted capacitor devices.

Another idea to add a very small amount of MWNTs to increase the surface area of the fabric did not yield fruitful results due to the poor penetration of CNTs into the microfibre fabric. In this case, the area properties of the hybrid electrode were the same as or better than those of the CNT electrode but the maximum voltage fell to $1.8 \mathrm{~V}$. 


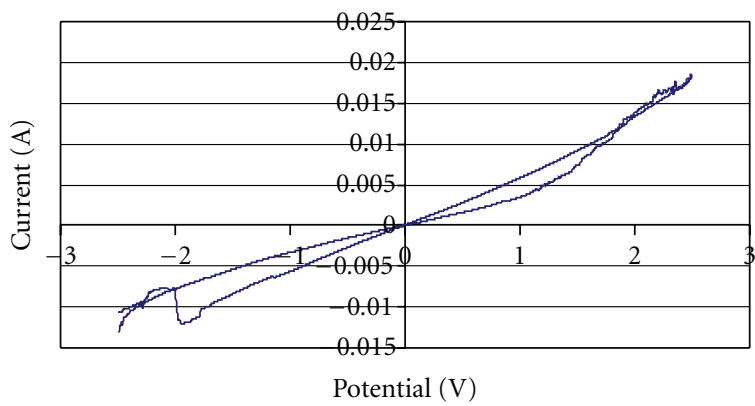

(a)

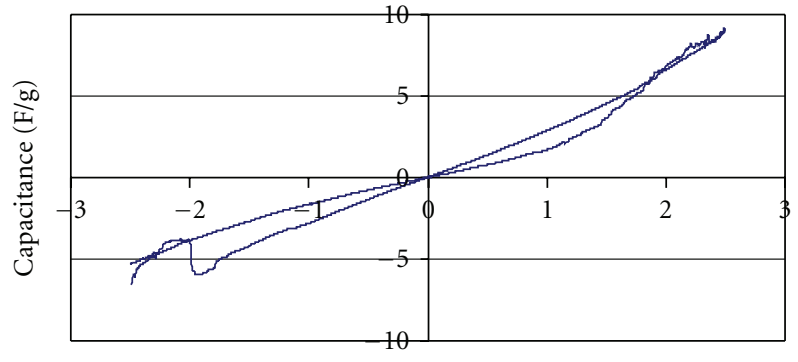

Potential (V)

(b)

FIGURE 10: Cyclic voltametry of EDLC CWF-CNT-GF/F capacitor from -2.5 to $2.5 \mathrm{~V}$ at a rate of $0.2 \mathrm{~V} / \mathrm{s}$ and specific capacitance of electrode; each carbon electrode has an area of $1 \mathrm{~cm}^{2}$ and mass of $20.2 \mathrm{mg}$ (20 mg CWF and $0.2 \mathrm{mg}$ CNTs).

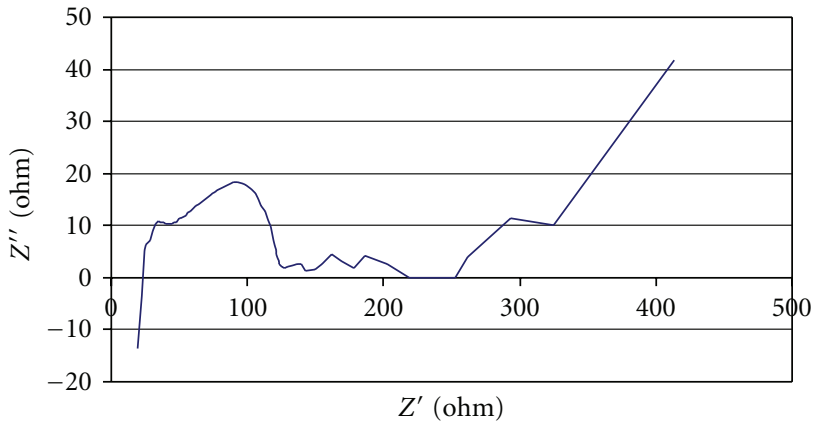

Figure 11: Nyquist plot from impedance testing of EDLC CFWCNT-GF/F capacitor between $1 \mathrm{MHz}$ and $0.03 \mathrm{~Hz}$; each carbon electrode has an area of $1 \mathrm{~cm}^{2}$ and mass of $20.2 \mathrm{mg}$.

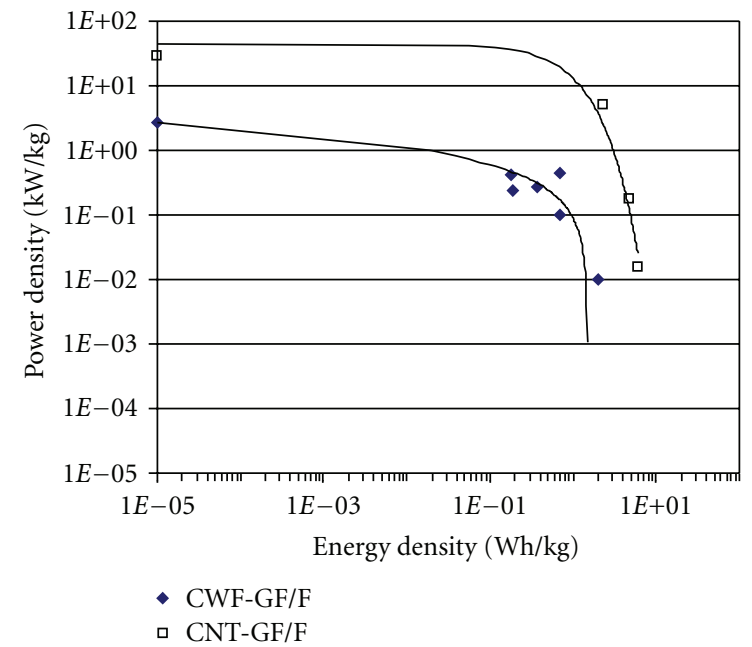

FIGURE 12: Ragone plots of two types of EDLC supercapacitors (full cells): the CWF-GF/F supercapacitor cell and the CNT-GF/F supercapacitor cell.

\section{Acknowledgment}

The authors would like to gratefully acknowledge the funding of this project by IeMRC/EPSRC UK, in the form of a research grant for which Dr. O. Moudam was employed as a research fellow.

\section{References}

[1] C. Arbizzani, M. Mastragostino, and F. Soavi, "New trends in electrochemical supercapacitors," Journal of Power Sources, vol. 100, no. 1-2, pp. 164-170, 2001.

[2] M. Kodama, J. Yamashita, Y. Soneda, H. Hatori, S. Nishimura, and K. Kamegawa, "Structural characterization and electric double layer capacitance of template carbons," Materials Science and Engineering B, vol. 108, no. 1-2, pp. 156-161, 2004.

[3] D. Hulicova, M. Kodama, and H. Hatori, "Electrochemical performance of nitrogen-enriched carbons in aqueous and non-aqueous supercapacitors," Chemistry of Materials, vol. 18, no. 9, pp. 2318-2326, 2006.

[4] D. Tashima, K. Kurosawatsu, M. Otsubo, and C. Honda, "Surface modification of carbon electrode for electric double layer capacitor," Plasma Processes and Polymers, vol. 4, no. 1, supplement, pp. S502-S506, 2007.

[5] E. G. Bushueva, P. S. Galkin, A. V. Okotrub et al., "Double layer supercapacitor properties of onion-like carbon materials," Physica Status Solidi B, vol. 245, no. 10, pp. 2296-2299, 2008.

[6] A. Nishino, "Capacitors: operating principles, current market and technical trends," Journal of Power Sources, vol. 60, no. 2, pp. 137-147, 1996.

[7] E. Heardman, C. Lekakou, and M. G. Bader, "Flow monitoring and permeability measurement under constant and transient flow conditions," Composites Science and Technology, vol. 64, no. 9, pp. 1239-1249, 2004.

[8] S. Amico and C. Lekakou, "An experimental study of the permeability and capillary pressure in resin-transfer moulding," Composites Science and Technology, vol. 61, no. 13, pp. 19451959, 2001.

[9] E. Heardman, C. Lekakou, and M. G. Bader, "In-plane permeability of sheared fabrics," Composites-Part A, vol. 32, no. 7, pp. 933-940, 2001.

[10] N. Shirshova, E. Greenhalgh, M. Shaffer, J. H. G. Steinke, P. Curtis, and A. Bismarck, "Structural polymer composites for energy storage devices," in Proceedings of the 17th International Conference on Composite Materials (ICCM '09), Edinburgh, UK, 2009.

[11] E. Frackowiak and F. Béguin, "Carbon materials for the electrochemical storage of energy in capacitors," Carbon, vol. 39, no. 6, pp. 937-950, 2001.

[12] V. L. Pushparaj, M. M. Shaijumon, A. Kumar et al., "Flexible energy storage devices based on nanocomposite paper," Proceedings of the National Academy of Sciences of the United States of America, vol. 104, no. 34, pp. 13574-13577, 2007. 
[13] R. Shi, L. Jiang, and C. Pan, "A single-step process for preparing supercapacitor electrodes from carbon nanotubes," Soft Nanoscience Letters, vol. 1, no. 1, pp. 11-15, 2011.

[14] R. Z. Ma, J. Liang, B. Q. Wei, B. Zhang, C. L. Xu, and D. $\mathrm{H}$. Wu, "Study of electrochemical capacitors utilizing carbon nanotube electrodes," Journal of Power Sources, vol. 84, no. 1, pp. 126-129, 1999.

[15] T. Bordjiba, M. Mohamedi, and L. H. Dao, "Synthesis and electrochemical capacitance of binderless nanocomposite electrodes formed by dispersion of carbon nanotubes and carbon aerogels," Journal of Power Sources, vol. 172, no. 2, pp. 991-998, 2007.

[16] Q. Guo, X. Zhou, X. Li et al., "Supercapacitors based on hybrid carbon nanofibers containing multiwalled carbon nanotubes," Journal of Materials Chemistry, vol. 19, no. 18, pp. 2810-2816, 2009.

[17] R. Kötz and M. Carlen, "Principles and applications of electrochemical capacitors," Electrochimica Acta, vol. 45, no. 15-16, pp. 2483-2498, 2000.

[18] A. K. Shukla, S. Sampath, and K. Vijayamohanan, "Electrochemical supercapacitors: energy storage beyond batteries," Current Science, vol. 79, no. 12, pp. 1656-1661, 2000.

[19] S. A. Hashmi, S. Suematsu, and K. Naoi, "All solidstate redox supercapacitors based on supramolecular 1,5diaminoanthraquinone oligomeric electrode and polymeric electrolytes," Journal of Power Sources, vol. 137, no. 1, pp. 145151, 2004.

[20] J. Huang, B. G. Sumpter, and V. Meunier, "A universal model for nanoporous carbon supercapacitors applicable to diverse pore regimes, carbon materials, and electrolytes," ChemistryA, vol. 14, no. 22, pp. 6614-6626, 2008.

[21] K. Hung, C. Masarapu, T. Ko, and B. Wei, "Wide-temperature range operation supercapacitors from nanostructured activated carbon fabric," Journal of Power Sources, vol. 193, no. 2, pp. 944-949, 2009.

[22] C. Lei, P. Wilson, and C. Lekakou, "Effect of PEDOT in carbon-based composite electrodes for electrochemical supercapacitors," Journal of Power Sources. In press.

[23] Z. Algharaibeh and P. G. Pickup, "An asymmetric supercapacitor with anthraquinone and dihydroxybenzene modified carbon fabric electrodes," Electrochemistry Communications, vol. 13, no. 2, pp. 147-149, 2011.

[24] S. Amico and C. Lekakou, "Flow through a two-scale porosity, oriented fibre porous medium," Transport in Porous Media, vol. 54, no. 1, pp. 35-53, 2004.

[25] S. Amico and C. Lekakou, "Mathematical modelling of capillary micro-flow through woven fabrics," Composites Part A, vol. 31, no. 12, pp. 1331-1344, 2000.

[26] A. K. Murugesh, A. Uthayanan, and C. Lekakou, "Electrophoresis and orientation of multiple wall carbon nanotubes in polymer solution," Applied Physics A, vol. 100, no. 1, pp. 135-144, 2010.

[27] R. J. Latham, S. E. Rowlands, and W. S. Schlindwein, "Supercapacitors using polymer electrolytes based on poly(urethane)," Solid State Ionics, vol. 147, no. 3-4, pp. 243-248, 2002.

[28] P. Staiti, M. Minutoli, and F. Lufrano, "All solid electric double layer capacitors based on Nafion ionomer," Electrochimica Acta, vol. 47, no. 17, pp. 2795-2800, 2002. 

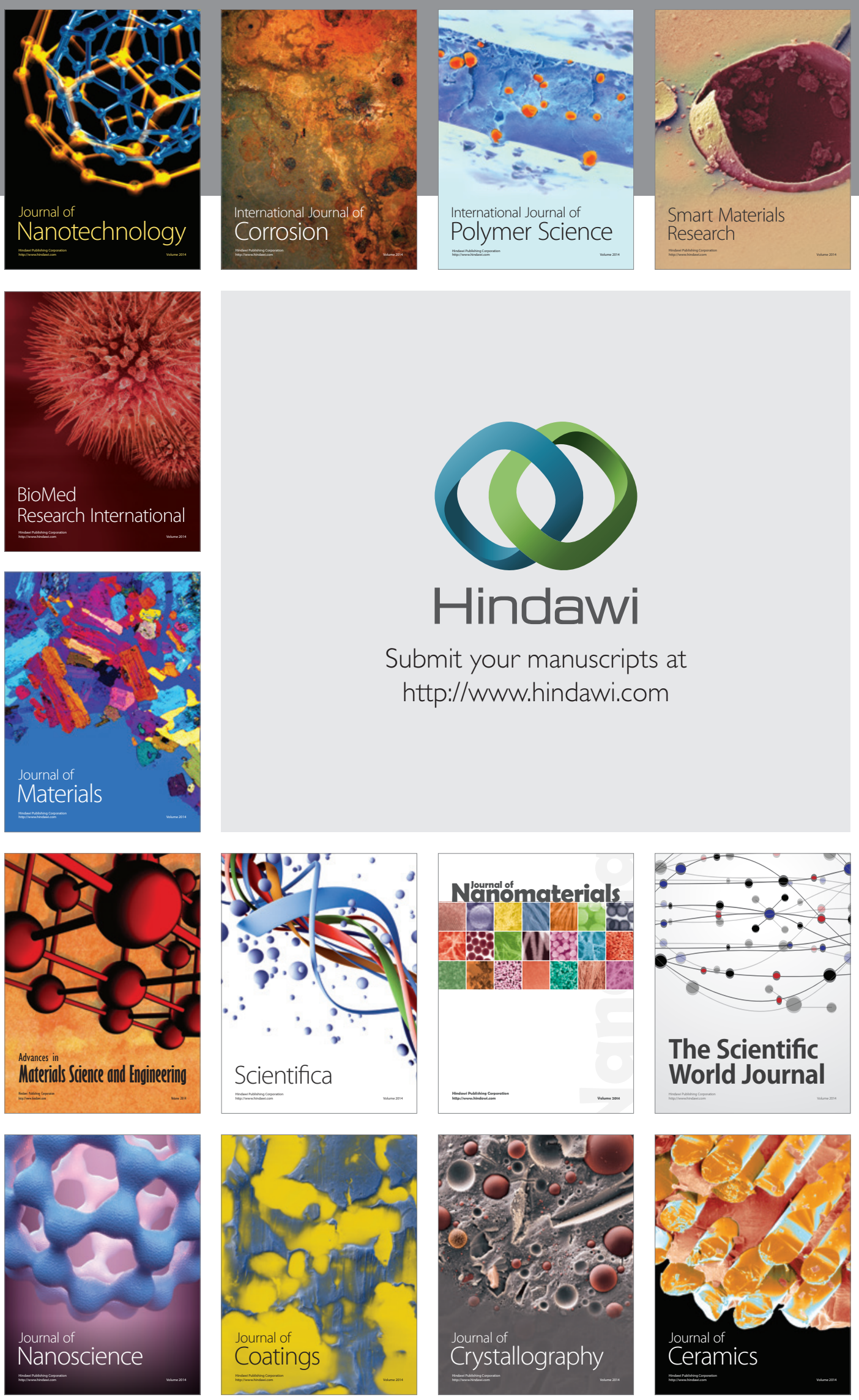

The Scientific World Journal

Submit your manuscripts at

http://www.hindawi.com

\section{World Journal}

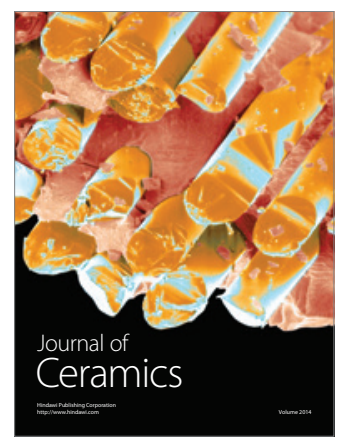

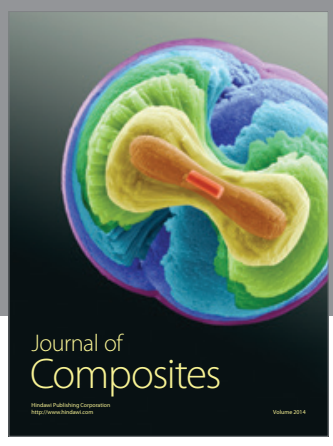
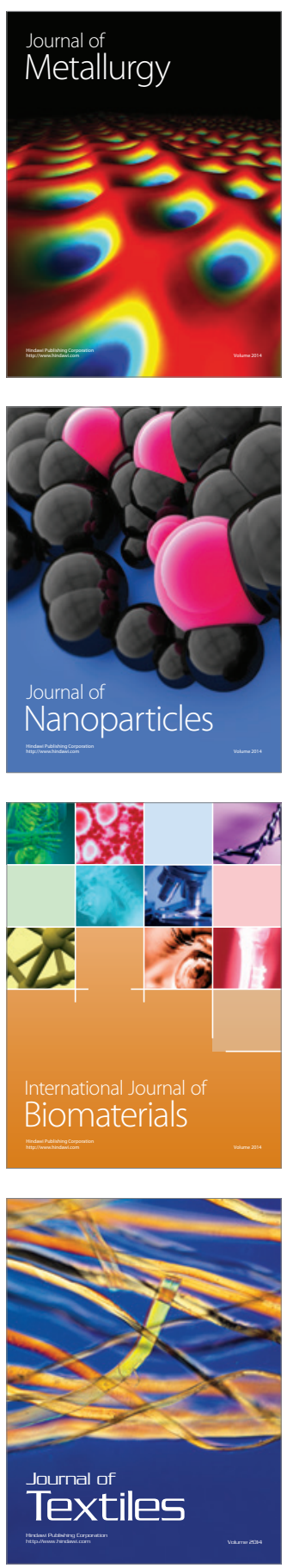